\title{
Origins of eponymous instruments in spine surgery
}

\author{
Morenikeji Buraimoh, MD, ${ }^{1}$ Azam Basheer, MD, ${ }^{2}$ Kevin Taliaferro, MD, ${ }^{3}$ Jonathan H. Shaw, MD, ${ }^{4}$ \\ Sameah Haider, MD, ${ }^{2}$ Gregory Graziano, MD, ${ }^{3}$ and Eugene Koh, MD1
}

\begin{abstract}
1Department of Orthopaedic Surgery, University of Maryland Medical Center, Baltimore, Maryland; Departments of ${ }^{2}$ Neurosurgery and ${ }^{3}$ Orthopedic Surgery, Henry Ford Hospital, Detroit, Michigan; and ${ }^{4}$ Wayne State University School of Medicine, Detroit, Michigan
\end{abstract}

\begin{abstract}
Every day, spine surgeons call for instruments named after surgical pioneers. Few know the designers or the histories behind their instruments. In this paper the authors provide a historical perspective on the Penfield dissector, Leksell rongeur, Hibbs retractor, Woodson elevator, Kerrison rongeur, McCulloch retractor, Caspar pin retractor system, and Cloward handheld retractor, and a biographical review of their inventors. Historical data were obtained by searching the HathiTrust Digital Library, PubMed, Google Scholar, Google Books, and Google, and personal communications with relatives, colleagues, and foundations of the surgeon-designers. The authors found that the Penfield dissectors filled a need for delicate tools for manipulating the brain and that the Leksell rongeur increased surgical efficiency during war-related laminectomies. Hibbs' retractor facilitated his spine fusion technique. Woodson was both a dentist and a physician whose instrument was adopted by spine surgeons. Kerrison rongeurs were developed in otology to decompress bone near the facial nerve. The McCulloch, Caspar, and Cloward retractors helped improve exposure during the emergence of new techniques, i.e., microdiscectomy and anterior cervical discectomy and fusion. The histories behind these eponymous instruments remind us that innovation sometimes begins in other specialties and demonstrate the role of innovation in improving patient care.
\end{abstract}

https://thejns.org/doi/abs/10.3171/2018.5.SPINE17981

KEYWORDS eponymous instruments; history of orthopedic surgery; history of neurosurgery; history of surgery

A NUMBER of the instruments we employ in surgery are eponymous. Nevertheless, their namesakes and the origins of the instruments remain obscure. Surgeons have explored the origins of eponymous instruments in the fields of hand surgery, plastic surgery, otolaryngology, and general orthopedics. ${ }^{16,23,31,32}$ Although spine surgery is one of the most innovative surgical fields, a historical perspective on eponymous spine instruments has not been written.

We aim to give a historical perspective on 8 spine instruments: the Penfield dissector, Leksell rongeur, Hibbs retractor, Woodson elevator, Kerrison rongeur, McCulloch retractor, Caspar pin retractor, and Cloward handheld retractor. Our list of instruments is by no means complete, and merely reflects instruments commonly used by the authors. We performed a nonsystematic search using the HathiTrust Digital Library, PubMed, Google Scholar, Google Books, and Google. Any non-English texts were translated into English with Google Translate (Google Inc.). We also communicated with relatives, colleagues, and foundations of the surgeon-designers.

\section{Wilder G. Penfield (1891-1976)}

The Penfield dissectors comprise a set of 5 blunt-tipped dissectors designed for gently manipulating neural tissues. The No. 4 Penfield (Fig. 1 left) is the workhorse dissector in spine surgery.

Wilder Penfield (Fig. 1 right), one of the 20th century's most influential brain surgeons, grew up in Spokane, Washington, and Hudson, Wisconsin. His father and grandfather were physicians. After matriculating from Princeton University, Penfield studied physiology at Oxford on a Rhodes Scholarship, and while there realized that neurophysiology was a "great unexplored field" primed for discovery. ${ }^{35}$ Penfield obtained his medical degree at Johns Hopkins University and interned at the Peter Bent Brigham Hospital in Boston, where he worked with Harvey Cushing.

ABBREVIATIONS ACDF = anterior cervical discectomy and fusion; $\mathrm{NYOH}=$ New York Orthopedic Hospital; NYU = New York University.

SUBMITTED September 7, 2017. ACCEPTED May 11, 2018.

INCLUDE WHEN CITING Published online September 14, 2018; DOI: 10.3171/2018.5.SPINE17981. 

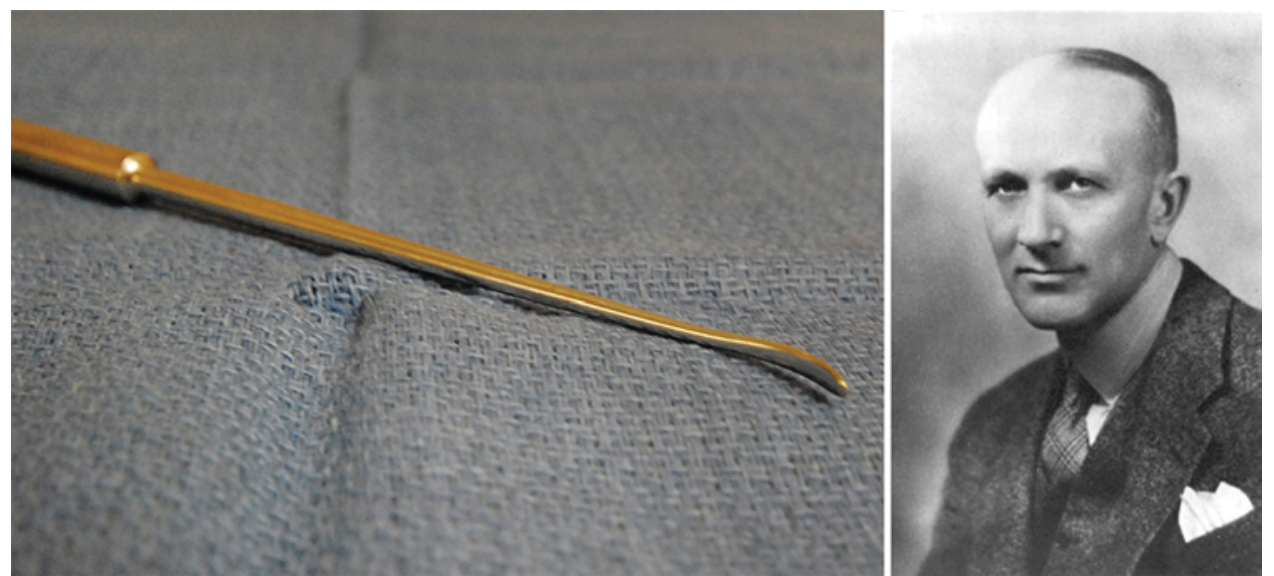

FIG. 1. Left: No. 4 Penfield dissector. Right: Photograph of Dr. Wilder G. Penfield. Photograph is in the public domain and was downloaded from https://commons.wikimedia.org/wiki/Wilder_Penfield\#/media/File:Wilder_Penfield.jpg. Figure is available in color online only.

He subsequently became a junior attending at Columbia Presbyterian Hospital in New York in 1921 under Allen Whipple. During this time, Penfield periodically observed neurosurgery clinics in Boston, Baltimore, and Philadelphia to continue learning his craft. ${ }^{11,35}$

Penfield also traveled to Europe to study neurophysiology, neurology, and neurosurgery. His famed dissectors were created while he was in Breslau, Germany, in 1928, learning Otfrid Foerster's technique for treating posttraumatic epilepsy. ${ }^{11,35}$ While awed by Foerster's techniques, Penfield noted a lack of gentle instruments for handling the brain. For example, he noted forceps and needles blunted by sponges being used to manipulate the brain, which he found particularly vexing. Before returning to the US, he enlisted a craftsman to make 5 "delicate dissectors." 35

Penfield moved to Montreal in 1928, and in 1934 founded the Montreal Neurological Institute. ${ }^{11}$ There, he perfected Foerster's technique for excising epileptic foci using brain mapping and local anesthesia. This brainmapping technique led to Penfield publishing his map of the motor homunculus, which today remains relatively un- changed ${ }^{40}$ At the end of his career, Penfield saw himself as an explorer, except unlike his "predecessors who used compasses and canoes to discover unknown lands," he used a scalpel and a small electrode to explore and map the human brain. ${ }^{36}$

\section{Lars G. F. Leksell (1907-1986)}

The Leksell laminectomy rongeur (Fig. 2 left) is used for spinous process removal, laminar thinning, and for some, central decompression during laminectomies. Lars Leksell (Fig. 2 right) was born in Fässberg Parish, Sweden, in 1907. His father was a businessman and his mother a talented porcelain decorator. As a teen, he liked gadgets and enjoyed creating radio receivers. Leksell originally intended to become a lawyer but turned to medicine after being impressed by orthopedic care he received after a motorcycle accident (D. Leksell, personal communication, 2017). Leksell completed his medical education at the Karolinska Institute in Sweden and began his neurosurgical training in 1935 under Herbert Olivercrona. Leksell's interest in neurosurgery stemmed from his interest in neu-
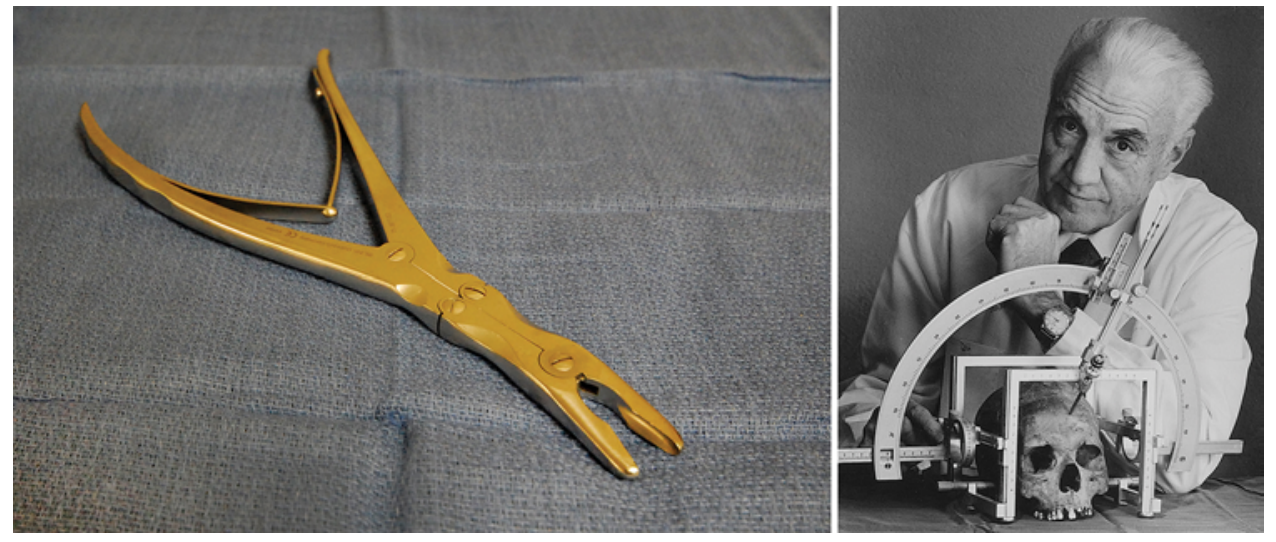

FIG. 2. Left: Leksell rongeur. Right: Photograph of Dr. Lars Leksell, courtesy of the Leksell Gamma Knife Society. Published with permission. Figure is available in color online only. 


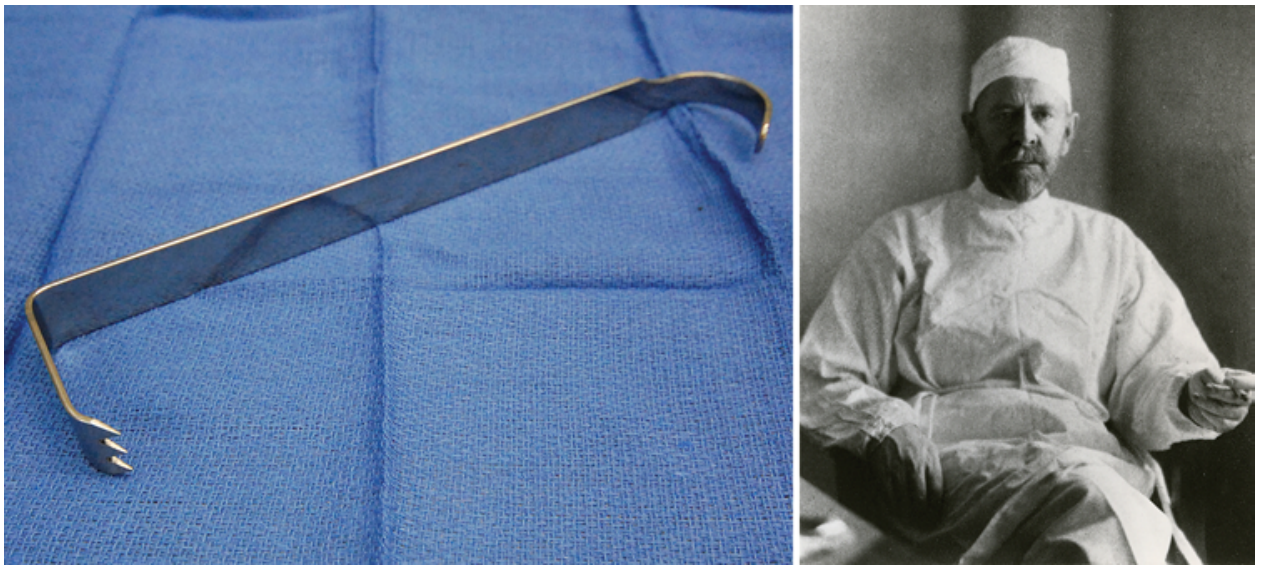

FIG. 3. Left: Hibbs retractor. Right: Dr. Russell A. Hibbs. Photograph by Doris Ullman-Jaeger. From The Faculty of the College of Physicians and Surgeons, Columbia University in the City of New York: Twenty-Four Portraits (New York: Paul B. Hoeber, 1919), courtesy Archives \& Special Collections, Columbia University Health Sciences Library. Published with permission. Figure is available in color online only.

rophysiology (D. Leksell, personal communication, 2017). This interest resulted in his discovery of the gamma motor neuron, which he presented as his $\mathrm{PhD}$ thesis in $1945 .^{26}$

In 1940, Leksell volunteered in the Finnish Winter War (1939-1945). ${ }^{26}$ The Leksell rongeur emerged during this time. Leksell designed the rongeur to improve the efficiency of laminectomy procedures for the removal of shell splinters from the spinal canal. ${ }^{12}$ The rongeur's manufacturer, Stille, compared this elegant instrument to a prima ballerina, whose "form and balance are essential to artistic achievement." Unbeknownst to Stille, Leksell loved classical ballet (D. Leksell, personal communication, 2017).

Leksell made many other contributions to neurosurgery. He developed a technique for ultrasound encephalography for head trauma in $1954 .{ }^{12} \mathrm{He}$ also advanced radiosurgery and invented the Gamma Knife. ${ }^{26}$ A desire to decrease the mortality rate associated with certain open brain surgeries drove Leksell's interest in radiosurgery (D. Leksell, personal communication, 2017). Without a doubt, Leksell showed a talent for innovation and instrument design early in his career. We continue to benefit from his drive to invent specific tools for clean, precise surgery.

\section{Russell A. Hibbs (1869-1932)}

The Hibbs retractor (Fig. 3 left) is commonly used for manual retraction of paraspinal muscles for exposure of the facet joints and lateral recesses. Russell A. Hibbs (Fig. 3 right) was born in Birdsville, Kentucky, in 1869. His father was a farmer, banker, and community leader. Hibbs attended Vanderbilt University and graduated from the University of Louisville School of Medicine in $1890 .^{33}$ $\mathrm{He}$ then practiced as a country doctor before moving to New York City in 1893 to intern in obstetrics at the New York Polyclinic Hospital. The following year, he took an appointment as a resident surgeon at the New York Orthopedic Dispensary and Hospital. After living in New York for only 6 years, he was appointed surgeon-in-chief of the New York Orthopedic Hospital (NYOH) at age 31..$^{33}$

At a time when most orthopedists were brace-makers first and surgeons second, Hibbs was a pioneer in the use of arthrodesis for the management of appendicular tubercular osteomyelitis. ${ }^{15}$ In 1909 , he developed a technique for knee arthrodesis. He learned from this the importance of using bridging bone graft and meticulously preserving periosteum to support new bone formation. ${ }^{19} \mathrm{He}$ applied this principle in treating Pott's disease in 1911. ${ }^{18}$ The original Hibbs spinal fusion was between the spinous processes; this was quickly extended to include the interlaminar spaces, and then the facet joints. Interestingly, Hibbs' productivity was fueled by a professional rivalry with Dr. Fred Albee, another New York orthopedist who independently developed a spinal fusion technique. Spine surgeons ultimately adopted Hibbs' technique. ${ }^{33}$ The timing of the development of the Hibbs retractor is unknown, but the retractor was designed for interlaminar exposure, where Hibbs performed fusion. Fittingly, it was the predominant retractor in the early days of spine fusion. ${ }^{39}$

Beyond being an innovator, Hibbs was a powerful administrator and dedicated teacher. He became a professor of orthopedics at Columbia University to teach orthopedic principles and inspire students to specialize in orthopedics. ${ }^{15}$ Likewise, Hibbs lobbied for funding to support young physicians seeking additional training in orthopedics after their internships. His efforts bore fruit in 1927, when the NYOH received a $\$ 1,000,000$ endowment to support paid clinical and research training for 8 students yearly, effectively starting an orthopedic residency program. That same year Hibbs donated $\$ 10,000$ to fund a library for orthopedic trainees at the NYOH. In 1947, graduates of the orthopedic residency program posthumously founded a traveling club for orthopedic education in Hibbs' name. This society is now a branch of the Scoliosis Research Society (SRS; http://www.srs.org/professionals/conferencesand-meetings/the-hibbs-society). The SRS also gives an annual research award in Dr. Hibbs' name. ${ }^{33}$

\section{E. W. Woodson (Dates Unknown)}

While the Woodson dental instrument (Fig. 4 left) was 

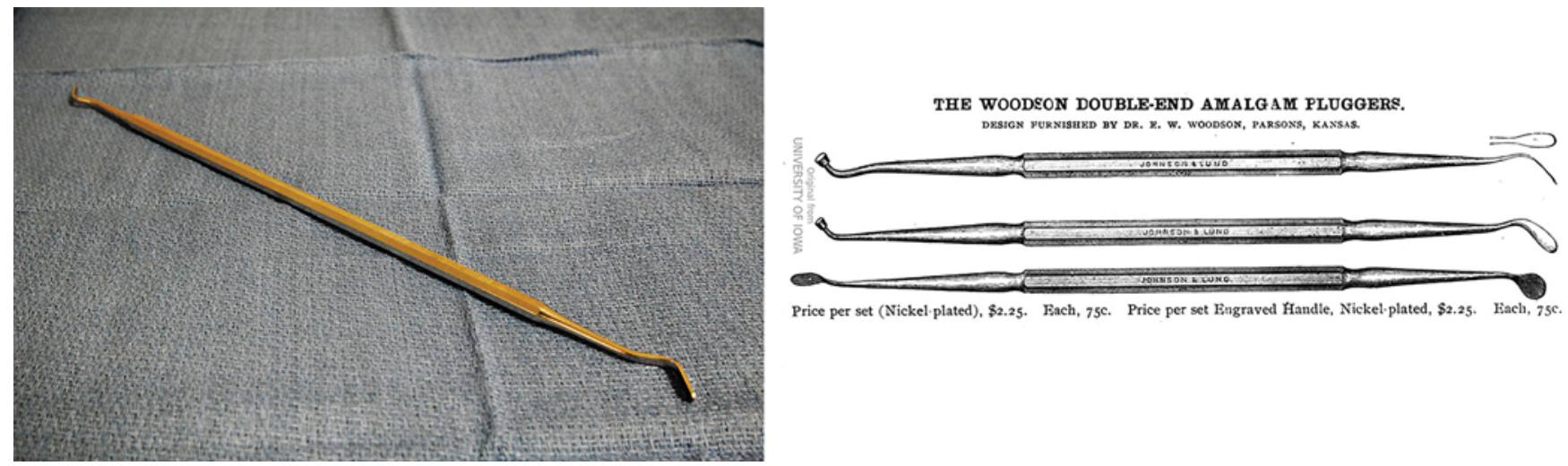

FIG. 4. Left: Modern Woodson dental instrument. Right: Photograph from 1896 of Dr. E. W. Woodson's double-ended amalgam pluggers (public domain). Figure is available in color online only.

originally a dental filling instrument, it has been adopted into spine surgery where it is often used as a feeler and dissector. The origin of the Woodson dental instrument's adoption into spine surgery remains unclear. However, we can attribute the instrument design to Dr. E. W. Woodson. ${ }^{10,38}$ Woodson posted periodical advertisements in Kansas between 1874 and 1885 showing that he practiced as a family physician in Woodsville, Kentucky, before practicing as a physician, surgeon, and dentist in Parsons, Kansas. In 1885 he left dentistry to resume a full-time physician practice and moved to El Dorado, Kansas. ${ }^{34,41}$ From that time, he remained an active member of the State Medical Society of Kansas. ${ }^{24,41}$ The Woodson instruments were patented in 1880, and were personalized versions of common dental filling instruments of the time rather than de novo designs..$^{38}$ The instruments (Fig. 4 right) had two working ends, an angulated spatula at one pole for carrying filler and a flat, circular head at the opposite pole for packing the mixture into cavities (condenser). Today, a version of the uppermost instrument in Fig. 4 (right), with a single- or double-ended paddle, is most commonly used in spine surgery. The bin-angle design of the paddle is useful because the working end is close to the handle's axis. This allows it to work around structures safely, for instance, feeling around a pedicle through a laminectomy exposure or peeling away adherent dura from the ventral thecal sac.

The adaptation of dental instruments into spine surgery, as in the case of the Woodson dental instrument, is not unusual. The Freer elevator, which is commonly used in orthopedics, is also a dental spatula ${ }^{14}$ In the last century we have seen continued cross-pollination between dentistry and spine surgery. ${ }^{8}$

\section{Philip D. Kerrison (1872-1944)}

The Kerrison rongeur (Fig. 5A and B) allows surgeons to safely remove bone while protecting deeper structures with its blunt distal endplate. Unknown to many, it was initially developed for otologic surgery. Philip D. Kerrison (Fig. 5C) was born in Charleston, South Carolina, in 1872. At age 24, he graduated from the State Medical College of South Carolina. He then attended New York University (NYU) where he completed his medical training in
1898. Thereafter, Kerrison traveled to Germany and Austria for specialized training in otology. ${ }^{1}$ After returning, he practiced as a professor of aural diseases and was an assistant surgeon at NYU until 1908. During this period, Kerrison presented his rongeur in The Laryngoscope and described its usefulness in the treatment of chronic suppurative otitis media, which required removal of a bone overlying the descending portion of the facial nerve. Until that time, the procedure was performed with a hammer and chisel. Damage to the facial nerve, and facial paralysis, was an infrequent but devastating complication. Kerrison surmised that by removing bone from inside-out, rather than outside-in, you could protect the facial nerve. ${ }^{21}$ Interestingly, Kerrison's bone forceps was similar to an instrument developed in Europe for sinus surgery in the 1890s (A. Mudry and R. Jackler, personal communication, 2018).

Kerrison's technique for bone removal is similar to the technique used by spine surgeons today. He introduced it into the tympanum with its tips "pointing upward" and advanced them until they touched the canal's bony roof; the handles were then approximated until the blades were "felt to crush or cut through bone." They were then withdrawn "bringing away a small portion of the upper canal wall." Kerrison also wittily included a technical point in his report on which any spine surgeon will agree, "if the surgeon forgets to clear the instrument after each removal of bone, it is apt to be broken by particles of bone becoming wedged between the blades." 21

How spine surgeons adopted the Kerrison punch remains unclear. Nevertheless, it has become an invaluable tool for spine surgery. After NYU, Kerrison continued his educational career at New York Polyclinic Medical School and his surgical career as consulting aural surgeon at Manhattan Eye, Ear, and Throat Hospital. ${ }^{42}$ During this time, he authored a textbook on otology. ${ }^{22} \mathrm{He}$ was also active in the New York Academy of Medicine, and the American Otological Society, for which he served as Vice President in $1925 .{ }^{1}$

\section{John A. McCulloch (1938-2002)}

The McCulloch retractor (Fig. 6 left) remains a popular 


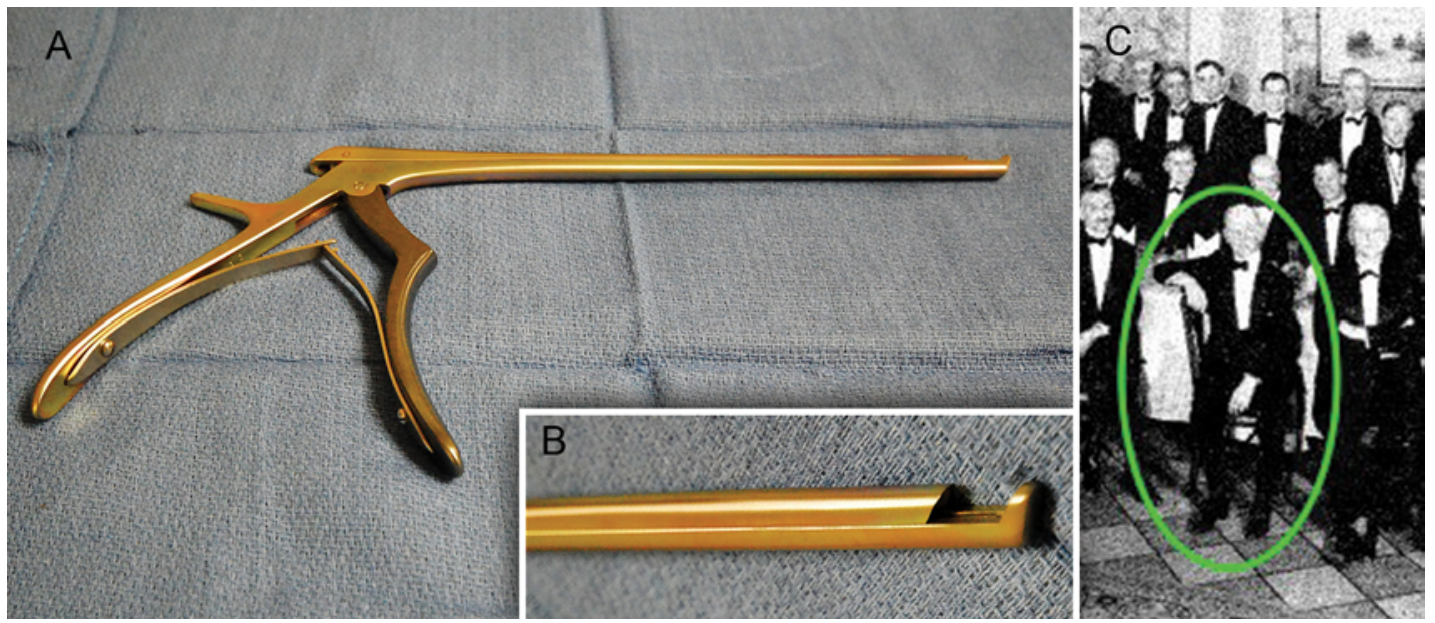

FIG. 5. A and B: Kerrison rongeur (A) and working end of Kerrison rongeur (B). C: Photograph of Dr. Philip D. Kerrison and fellow guests at the 65th Annual Meeting of the American Otological Society (AOS), courtesy of the AOS. Published with permission. Figure is available in color online only.

instrument for exposure during lumbar microdiscectomy. John McCulloch (Fig. 6 right) was born in Canada in 1938. He completed his medical and orthopedic education at the University of Toronto, and then remained to complete a spine fellowship under Ian Macnab. ${ }^{43}$ McCulloch practiced at St. Michael's Hospital in Toronto before becoming Professor of Orthopedics at Northeastern Ohio University College of Medicine. He championed the use of the microscope in spine surgery throughout his career and authored a number of works on microsurgery. It appears that his interest in microsurgery began as a patient. He suffered a herniated lumbar disc and underwent a microdiscectomy. Within 5 years of the surgery, he became an international expert in microsurgery. ${ }^{13}$

McCulloch designed the frame retractor around 1990 to overcome the shortcomings of then-current self retainers used in microdiscectomy, which included the Williams, Meyerding, and Casper retractors. These retractors did not hold properly (P. Young, personal communication, 2017). ${ }^{30}$ McCulloch had preferred the Meyerding because it was effective, having a hook for retracting the interspinous ligament and a toothed blade for holding muscle. The McCulloch similarly juxtaposed a hook and a toothed blade. ${ }^{9,30}$ These working ends were modular and ratcheted along parallel bars, similar to the retractors used by Caspar and Cloward at that time in the cervical spine. ${ }^{44}$ The tip of the hook was designed to sit on the posterior onehalf to two-thirds of the interspinous ligament, where the ligament is strongest (D. Wong, personal communication, 2018). The McCulloch's posts were shaped like a square to allow more force to be applied, facilitating better self-retention. Additionally, the retractor was originally colored black to minimize any glare from the light of a microscope (P. Young, personal communication, 2017).

McCulloch will be remembered most for his excellence as an educator. He authored 7 textbooks. He gave 304 scientific presentations and instructional course lectures. ${ }^{13}$ He also chaired the first trainee cadaver lab course in the US along with Dr. Paul Young (D. Wong, personal com- munication, 2018). Not surprisingly, McCulloch was twice recognized for research excellence, receiving the International Society for the Study of the Lumbar Spine's Volvo prize in 1975, and the North American Spine Society's Wiltse Award in 2001.13

\section{Wolfhard Caspar (1938-Present)}

The Caspar pin and vertebral body distractor (Fig. 7A and $\mathrm{B}$ ) remain key instruments for disc space preparation during anterior cervical discectomy and fusion (ACDF), and cervical disc replacement. Wolfhard Caspar (Fig. 7C) was born in Ventspils, Latvia, in 1938 (W. Caspar via Dr. Tobias Pitzen, personal communication, 2018). His childhood aspiration was to become an Air Force pilot, but he decided to become a physician like his father and grandfather after learning that his vision was inadequate for piloting. ${ }^{3,20}$ Caspar obtained his medical degree at the University of Saarland in Homberg, Germany, and his doctorate in philosophy in Budapest, Hungary. He completed

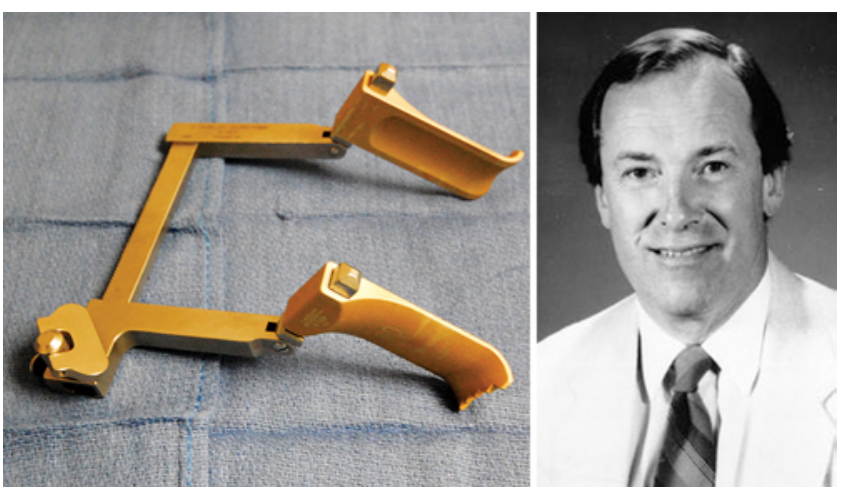

FIG. 6. Left: McCulloch muscle retractor. Right: Photograph of Dr. John A. McCulloch, courtesy of Dr. Robert D. Fraser. Published with permission. Figure is available in color online only. 


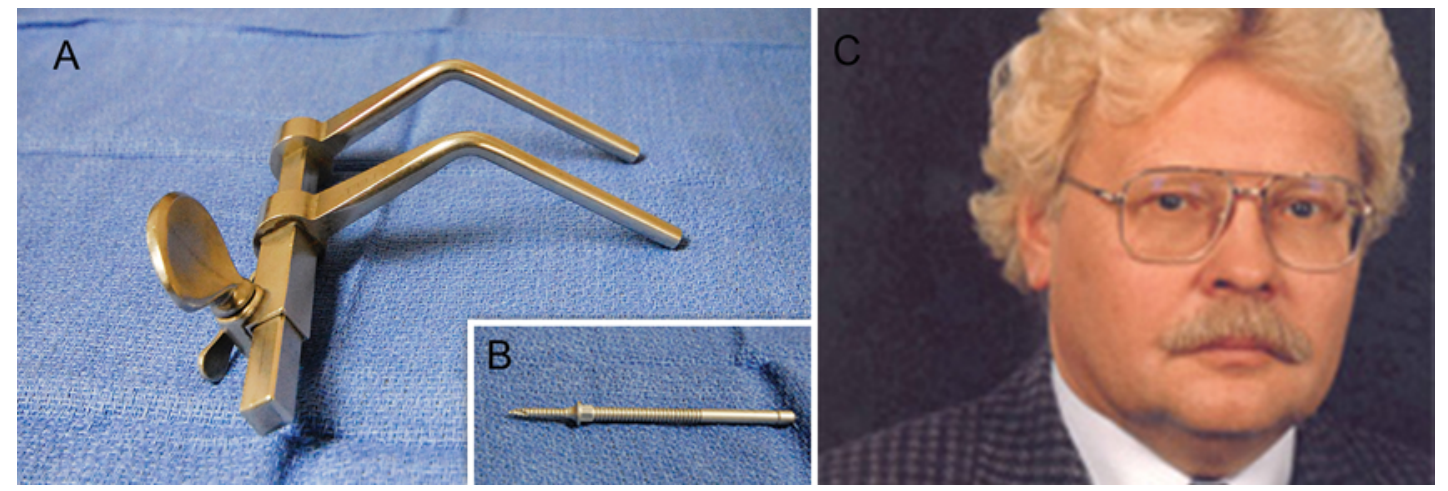

FIG. 7. A and B: Caspar retractor (A) and Caspar pin (B). C: Photograph of Dr. Wolfhard Caspar, courtesy of Deutsche ArthroseHilfe e.V. Published with permission. Figure is available in color online only.

neurosurgical training at the University of Saarland where he ultimately spent his entire career. Interestingly, Caspar believes that he fell into neurosurgery merely by chance (W. Caspar via T. Pitzen, personal communication, 2018).

The Caspar pins and vertebral distractor were part of the instrument set for anterior cervical fusion with plate fixation that Caspar designed in 1979. This was the first standardized set for anterior cervical surgery. After the popularization of the ACDF technique by Smith-Robinson and Cloward beginning in 1958, spine surgeons expanded the indications for anterior cervical fusion from degenerative pathologies to tumors and trauma and began plating the cervical spine. However, standardized tools were still lacking for what Caspar believed were the 3 fundamental parts of the modern anterior cervical procedure: 1 ) wound exposure; 2) alignment, decompression, and fusion; and 3) fixation. This led to problems with poor screw placement and screw loosening, and the associated surgical complications. $3,17,37$

The Caspar pin-based vertebral distractor was designed for alignment, decompression, and fusion, and was radically different from the intervertebral spreader commonly in use. It docked into the vertebral bodies instead of the disc space, allowing surgeons to gain complete exposure of the disc space. According to Caspar, surgeons could now distract over two interspaces and perform resections for trauma or tumors, use larger grafts, and limit endplate violation. ${ }^{42}$ Brodke and Zdeblick corroborated these findings in 1992 and added that the pin distractor system "eased osteophyte resection during anterior foraminotomies." 2 The original Caspar pins came in two thread lengths, $14 \mathrm{~mm}$ and $16 \mathrm{~mm}$, no different from today. ${ }^{3}$

Caspar was also an innovator of microsurgery, which he adopted in 1975. Along with Gaze Yasargil and Robert Williams, Caspar proved microsurgery's usefulness in the spine when he applied it to the lumbar spine for disc herniations. ${ }^{29}$ Thereafter, more than 200 surgeons from across the world traveled to Germany to learn microsurgery from Caspar. ${ }^{20}$ It has been said by one of Caspar's fellows that "for Dr. Caspar, technique and instrumentation were inseparable in his quest for surgical precision."17 Today we owe much to Caspar's drive for surgical excellence.

\section{Ralph B. Cloward (1908-2000)}

The Cloward handheld retractor (Fig. 8 left) is used during the anterior cervical approach for initial exposure and elevation of the vertebrae and longus colli muscles. Ralph Cloward (Fig. 8 right) was born in Salt Lake City, Utah, in 1908. His great grandparents were Mormon pioneers; his great grandfather was the shoemaker in Brigham Young's party. Cloward grew up on the family farm in Utah. He was a talented clarinetist and played in the Salt Lake Symphony during high school. In 1926, he moved to Honolulu to attend the University of Hawaii and to join his father, who was commissioned there as an army otolaryngologist. Cloward finished college at the University of Utah and entered into their 2-year preclinical program in 1930. He then completed his final years of medical school and internship at Rush Medical School and St. Luke's Hospital in Chicago. Cloward's fascination with the nervous system began during preclinical anatomy and matured while an intern under the mentorship of Dr. Eric Oldberg. Cloward completed a 3-year residency under Dr. Percival Bailey at the University of Chicago and then returned to Honolulu in 1938 to join his father's multispecialty group. ${ }^{7}$ During World War II, Cloward remained the only available American neurosurgeon in the Pacific theater, and his related exploits are well documented..$^{28}$

Cloward independently devised a technique and instrumentation for ACDF and published his technique in $1958 .{ }^{6}$ This instrumentation included the Cloward vertebral spreader and the Cloward handheld retractor. The handheld retractor was used for temporary retraction of the longus colli, prior to placement of his modular self-retainer. The broad nature of the retractor most likely minimized point pressure during retraction. ${ }^{4}$ The Cloward handheld retractor continues to be used as it was originally intended, and the Cloward vertebral spreader is preferred by some today over the Caspar pin distractor.

Cloward was a trailblazer. His most enduring contributions to neurosurgery and spine surgery were his techniques and instrumentation for interbody fusion, including posterior lumbar interbody fusion. ${ }^{7,28}$ Relatedly, he set up the first bone bank in the US, from which he obtained fresh-frozen bone graft for fusions. ${ }^{28}$ Unfortunately like many pioneers before, Cloward's innovations were ini- 

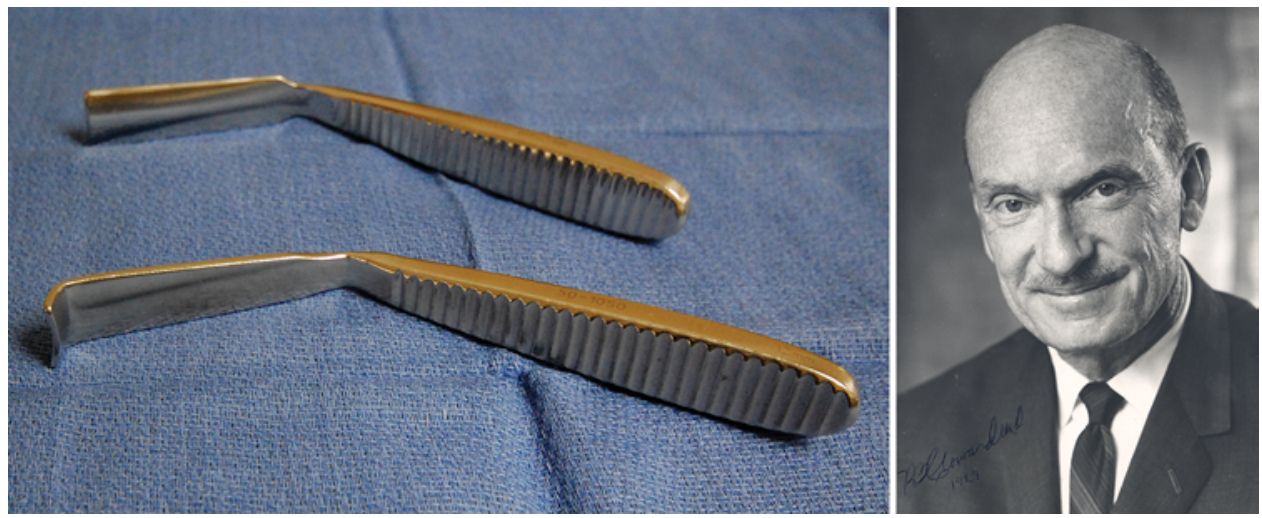

FIG. 8. Left: Cloward handheld retractor. Right: Photograph of Dr. Ralph B. Cloward, courtesy of the American Association of Neurological Surgeons. Published with permission. Figure is available in color online only.

tially met with bitter resistance. He once noted, "you can always tell a pioneer. He's the one with all the arrows in his back." Ultimately, Cloward was recognized for his contributions to spine surgery, and in 1990 he was awarded the first lifetime achievement award bestowed by the joint section of the CNS/AANS. ${ }^{25}$ Today, his contributions continue to be honored through the Cloward fellowship and the Cloward Award. ${ }^{25,28}$

\section{Discussion}

To our knowledge, this is the first review article to discuss the history of eponymous instruments in spine surgery. The aims of this historical perspective were to recognize the designers of the selected surgical instruments and to explore the historical factors surrounding their invention. The reviewed instruments emerged from the fields of dentistry, neurosurgery, orthopedic surgery, and otology. A desire to improve surgical safety (Penfield and Kerrison), operative efficiency (Leksell and Hibbs), or both (McCulloch and Cloward handheld retractors, and Caspar pin) drove the invention of the surgeon-designed instruments. The shape of the Woodson instrument supports an argument that it was adopted into spine surgery for both safety and efficiency.

We now appreciate the tools of the noted surgeondesigners, but we should also appreciate that the surgical innovations associated with new, radical ideas and techniques were sometimes met with bitter resistance. Both Hibbs and Cloward were ostracized by respective orthopedic and neurosurgery colleagues long before they were celebrated. ${ }^{7,15}$ This phenomenon was described by the 19th-century German philosopher Arthur Schopenhauer, who said that all truths are ridiculed and violently opposed before gaining acceptance. ${ }^{5}$ Caspar further corroborates this idea (W. Caspar via T. Pitzen, February 15, 2018). Hence, innovators must be determined and ready for said challenge.

\section{Conclusions}

Reviewing the personal lives of the included surgeondesigners and the circumstances surrounding the origins of their instruments affords us an opportunity to honor their work. It also facilitates a better understanding of the utility of their instruments and the role of innovation in the history of spine surgery.

\section{Acknowledgments}

We thank Drs. Robert Fraser, Paul Young, David Wong, Louis Harkey, Dan Leksell, Wolfhard Caspar, Tobias Pitzen, Robert Jackler, and Albert Mudry for sharing personal recollections and providing primary sources. We thank Dr. Robert Fraser, the Leksell Gamma Knife Society, Columbia University Health Sciences Library, American Association of Neurological Surgery, and Deutsche Arthrose-Hilfe e.V., as well as Thom Pinho, for assistance with figure preparation. We thank Susan MacPhee for assistance with manuscript preparation.

\section{References}

1. American Laryngological, Rhinological and Otological Society: In memoriam: Dr. Phillip D. Kerrison, 1861-1944. Trans Am Otol Soc 33:321, 1944

2. Brodke DS, Zdeblick TA: Modified Smith-Robinson procedure for anterior cervical discectomy and fusion. Spine (Phila Pa 1976) 17 (10 Suppl):S427-S430, 1992

3. Caspar W: Anterior Cervical Fusion and Interbody Stabilization with the Trapezoidal Osteosynthetic Plate Technique (D-78532), ed 10. Tuttlingen: Aesculap AG \& Co., 1997

4. Chambliss Harrod C, Klare C, Albert TJ: Anterior cervicothoracic approach, in Zdeblick TA, Albert TJ (eds): Master Techniques in Orthopaedic Surgery: The Spine, ed 3. Philadelphia: Wolters Kluwer Health, 2014

5. Chu M: The 3 stages of truth in life. Huffington Post. July 28, 2016 (http://www.huffingtonpost.com/melissa-chu/the3-stages-of-truth-in-_b_11244204.html) [Accessed June 8, 2018]

6. Cloward RB: The anterior approach for removal of ruptured cervical disks. J Neurosurg 15:602-617, 1958

7. Cloward RB, Selby RC: Ralph B. Cloward, MD, interviewed by Roy C. Selby, MD [video]. Leaders in Neuroscience: An Archives Video-Interview Series. Rolling Meadows, IL: American Association of Neurological Surgeons, (https:// youtu.be/TiYkC9Za8E8) [Accessed June 8, 2018]

8. Conley A, Tye GW, Ward JD, Myseros JS: Occult spinal dysraphism and the tethered spinal cord, in Benzel EC (ed): Spine Surgery: Techniques, Complication Avoidance, and 
Management, ed 3. Philadelphia: Saunders Elsevier, 2012, pp 1141-1154

9. Delamarter R, McCulloch J: Microdiscectomy and microsurgical laminotomies, in Frymoyer JW (ed): The Adult Spine: Principles and Practice, ed 2. Philadelphia: LippincottRaven, 1997, pp 1961-1986

10. Dental Office and Laboratory: Operating instruments [advertisement]. Dental Office and Laboratory 10:3-17, 1896

11. Eccles J, Feindel W: Wilder Graves Penfield, 26 January 1891-5 April 1976. Biogr Mem Fellows R Soc 24:473-513, 1978

12. Eklöf B, Lindström K, Persson S: Ultrasound in Clinical Diagnosis: From Pioneering Developments in Lund to Global Application in Medicine. Oxford: Oxford University Publishing, 2012, pp 44-46

13. Fraser RD: In memoriam: John McCulloch, MD, FRCSC 1938-2002. Spine (Phila Pa 1976) 27:2418, 2002

14. Freer OT: The window resection operation for the correction of deflections of the nasal septum. J Am Med Assoc 61:1391-1398, 1903

15. Goodwin GM, Lambert SW, Vogel KM: Russell A. Hibbs, Pioneer in Orthopedic Surgery, 1869-1932. New York: Columbia University Press, 1935

16. Harijan A, Halvorson EG: Eponymous instruments in plastic surgery. Plast Reconstr Surg 127:456-465, 2011

17. Harkey HL, Tawfik T: If it ain't broke, don't fix it. World Neurosurg 93:467-468, 2016

18. Hibbs RA: An operation for progressive spinal deformities: a preliminary report of three cases from the service of the orthopaedic hospital. 1911. Clin Orthop Relat Res 460:17-20, 2007

19. Hibbs RA: XII. An operation for stiffening the knee-joint: with report of cases from the service of the New York Orthopaedic Hospital. Ann Surg 53:404-407, 1911

20. Hoppe A: Weltpreis an Dr. Wolfhard Caspar. Espelkamper Zeitung. October 10, 2012 (http://www.soederblom.de/ aktuelles/article/weltpreis-an-dr-wolfhard-caspar.html) [Accessed June 8, 2018]

21. Kerrison PD: A bone forceps for use in tympanic surgery; its value in safe-guarding the facial nerve in the radical operation for chronic suppurative otitis media. Laryngoscope 14:337-345, 1904

22. Kerrison PD: Diseases of the Ear. Philadelphia: J. B. Lippincott Company, 1930

23. Lamprell L, Ahluwalia S: Who has been hiding in your tonsillectomy tray? Eponymous instruments in tonsillectomy surgery. J Laryngol Otol 129:307-313, 2015

24. Lanphear E: Kansas State Medical Society, in Lanphear SE (ed): Kansas City Medical Index. Kansas City, MO: Hudson-Kimberly Publishing Company, 1888, Vol 9, pp 81-83

25. Lin PS: In memorium: Ralph B. Cloward, MD (1908-2000). Spine (Phila Pa 1976) 26:2303-2304, 2001

26. Lindquist C, Kihlström L: Department of Neurosurgery, Karolinska Institute: 60 years. Neurosurgery 39:1016-1021, 1996

27. Lozano AM, Gildenberg PL, Tasker RR: Textbook of Stereotactic and Functional Neurosurgery. Berlin: Springer, 2009

28. Maiti TK, Konar SK, Bir SC, Kalakoti P, Nanda A: Ralph Bingham Cloward (1908-2000): Spine polymath. World Neurosurg 89:562-567, 2016
29. Mayer HM: Minimally Invasive Spine Surgery: A Surgical Manual, ed 2. Berlin: Springer, 2006, pp 8-12

30. McCulloch JA: Principles of Microsurgery for Lumbar Disc Disease. New York: Raven Press, 1989

31. Meals C, Wang J: Origins of eponymous orthopaedic equipment. Clin Orthop Relat Res 468:1682-1692, 2010

32. Meals CG, Meals RA: A history of surgery in the instrument tray: eponymous tools used in hand surgery. J Hand Surg Am 32:942-953, 2007

33. Miller DJ, Vitale MG: Dr. Russell A. Hibbs: pioneer of spinal fusion. Spine (Phila Pa 1976) 40:1311-1313, 2015

34. Parsons Weekly Sun: Recommendation [advertisement]. Parsons Weekly Sun. August 15, 1874; 3 (col. 1)

35. Penfield W: No Man Alone: A Neurosurgeon's Life. Boston: Little, Brown \& Company, 1977, pp 36, 154-182

36. Penfield W, Steelman H: The treatment of focal epilepsy by cortical excision. Ann Surg 126:740-761, 1947

37. Pitzen T, Caspar W: Operative Therapie von Malignomen der Halswirbelsäule Ein differenziertes chirurgisches Behandlungskonzept: Schlußwort. Dtsch Arztebl Ausg A 95:A-423, 1998

38. Southern Dental Journal and Luminary: Amalgam, GuttaPercha, and Plastic Filling Instruments [advertisement]. Southern Dental Journal and Luminary 5:435, 1886

39. Taylor GM: A simple retractor for spinal surgery. J Bone Joint Surg Am 28:183-184, 1946

40. Todman D: Wilder Penfield (1891-1976). J Neurol 255:11041105,2008

41. Walnut Valley Times: Endorsement [advertisement]. Walnut Valley Times. December 18, 1885; 3 (col. 3)

42. Walsh T (ed): In memoriam: Philip D. Kerrison, M.D., 18721944. Laryngoscope 54:93, 1944

43. Wong DA: John Alexander McCulloch. Spine J 2:156, 2002

44. Young PH: Microsurgery of the Cervical Spine. New York: Raven Press, 1991

\section{Disclosures}

The authors report no conflict of interest concerning the materials or methods used in this study or the findings specified in this paper.

\section{Author Contributions}

Conception and design: Buraimoh, Graziano. Acquisition of data: Buraimoh, Basheer, Taliaferro, Shaw, Haider. Analysis and interpretation of data: Buraimoh, Taliaferro, Haider. Drafting the article: Buraimoh, Basheer, Taliaferro, Shaw, Haider. Critically revising the article: Buraimoh, Basheer, Koh. Reviewed submitted version of manuscript: all authors. Approved the final version of the manuscript on behalf of all authors: Buraimoh. Administrative/technical/material support: Buraimoh. Study supervision: Buraimoh, Koh.

\section{Correspondence}

Morenikeji Ayodele Buraimoh: University of Maryland, Baltimore, MD. aburaimoh@gmail.com. 